\title{
5 | 2021
}

66. Jahrgang

5. März 2021

S. $169-208$

PVSt 1062

Zeitschrift für deutsches, europäisches

Die Aktiengesellschaft

Herausgegeben von Prof. Dr. Heinz-Dieter Assmann und Prof. Dr. Mathias Habersack die-aktiengesellschaft.de

in Verbindung mit VorsRiBGH Prof. Dr. Ingo Drescher · Prof. Dr. Volker Emmerich ·

PräsBVerfG Prof. Dr. Stephan Harbarth · Prof. Dr. Jens Koch · Prof. Dr. Hans-Joachim Mertens ·

Prof. Dr. Dr. h.c. Uwe H. Schneider · RA Prof. Dr. Jochen Vetter · Prof. Dr. Dr. h.c. Wolfgang Zöllner
Zwei, die zusammengehören:

\section{ZEITSCHRIFT}

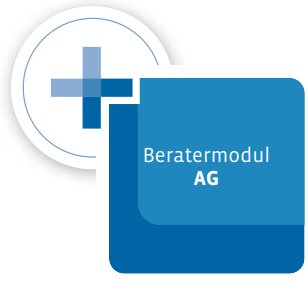

Profitieren Sie von Ihrer ONLINE-DATENBANK
Aufsätze > Christoph H. Seibt / Alexander Klausmann - Einvernehmliche

Dienstbefreiung von Vorstandsmitgliedern 169

Dirk Wasmann - Zur Evaluation des Spruchverfahrens: Kein Abschaffungs- und überschaubarer Änderungsbedarf - Die Richter können es richten

Steuer-Journal > Burkhard Binnewies / Eugen Mehlhaf - Einschränkbarkeit der Quellensteuerentlastung bei Dividendenzahlungen in die Schweiz (und andere Drittstaaten) nach $§ 50 d$ Abs. 3 EStG

Rechtsprechung > Außensteuerrecht: Einkünftekorrektur nach $\S 1$ Abs. 1 AStG bei gewinnmindernder Abschreibung auf unbesicherte Darlehensund Zinsforderung im Konzern (BFH, Urt. v. 19.2.2020 - I R 19/17)

Aufsichtsrat: Gerichtliche Bestellung der Aufsichtsratsmitglieder analog § 104 AktG (OLG München, Beschl. v. 22.12.2020 -

$31 \mathrm{Wx} 436 / 20)$

Vorstandsrecht: Vertretung einer Genossenschaft in Zeiten der COVID-19-Pandemie (OLG Naumburg, Beschl. v. 6.11.2020 $9 \mathrm{~W} \times \mathrm{9} / 20)$

Prospekthaftung: Prospektfehler im Rahmen einer ICO (LG Berlin, Urt. v. 27.5.2020 - 20 322/18) .204

Rechts-Report Thorsten Kuthe / Gero Lingen - Keine gerichtliche Bestellung von Aufsichtsratsmitgliedern bei Anfechtung der Aufsichtsratswahl R68 


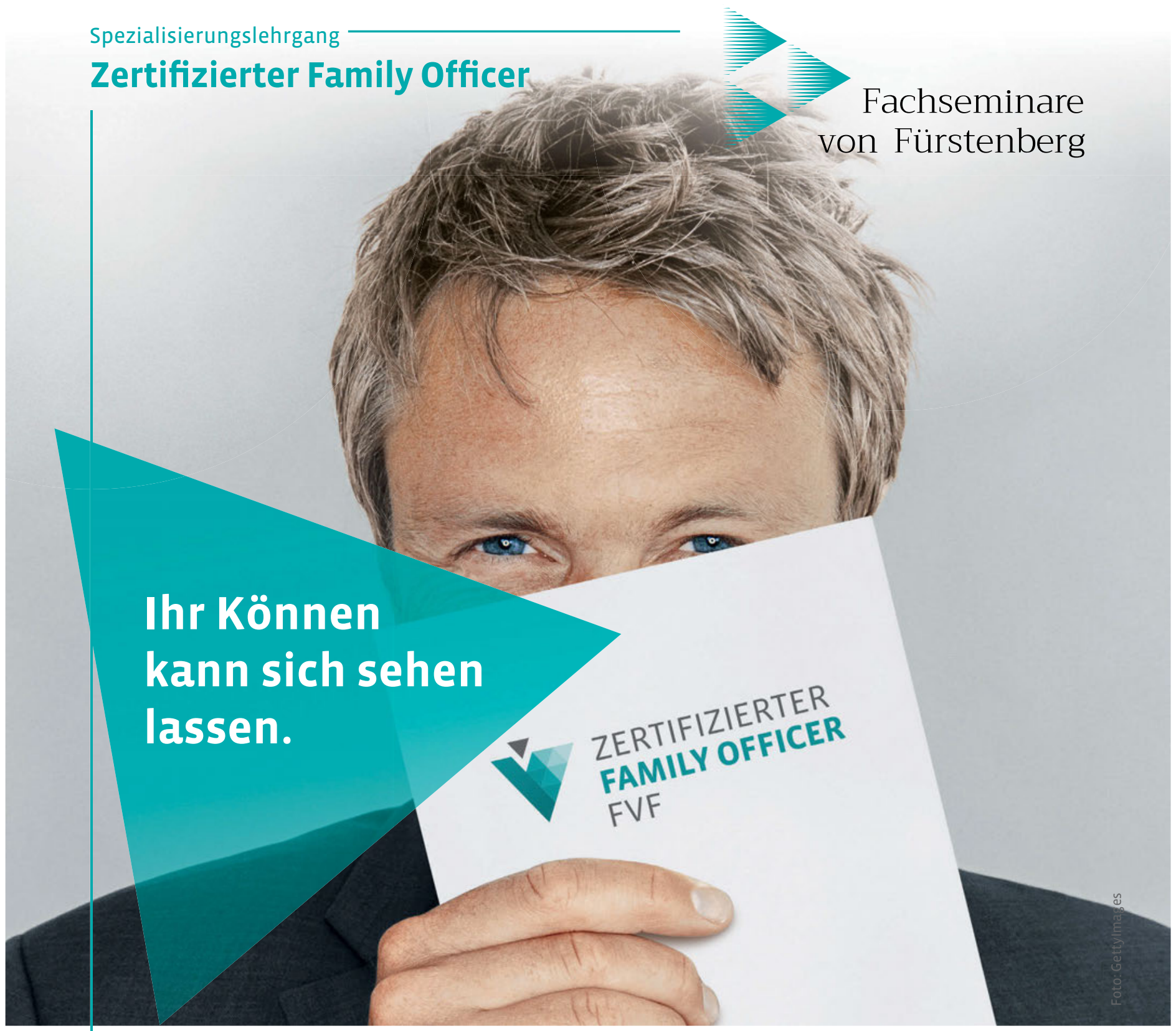

\section{Vermögensverwaltung braucht Qualitåtsstandards.}

Nutzen Sie unseren zertifizierten Abschluss für Ihren Wettbewerbsvorteil.

Der Fachbereich „Family Office“ ist ein dynamischer Wachstumsmarkt, auf den immer mehr Anbieter mit unterschiedlichstem fachlichen Background drängen. Heben Sie sich von der Masse ab und empfehlen Sie sich bei potenziellen Klienten mit Ihrem persönlichen Zertifikat.

Überzeugen Sie durch

- nachgewiesene Qualitätsstandards

- mehr Transparenz im Qualifikationsprofil

- die Vermittlung von Sicherheit und Vertrauen

- eine aussagekräftige Orientierungshilfe
Profitieren Sie von

- dem einzigartigen Spezialisierungslehrgang mit zertifiziertem Abschluss

- interdisziplinärer Wissensvermittlung

- praxisorientierten Best-Practice-Beispielen

- renommierten Referenten

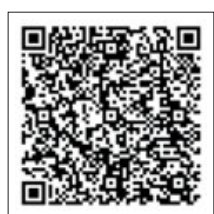

